\title{
Construction of Surfactant-Membrane Electrodes Selective for Sodium Dodecyl Sulfate in Poly(ethylene oxide)-Surfactant Mixtures
}

\author{
Ivanise Maria Rizzatti*, Dilson R. Zanette and Dino Zanette \\ Departamento de Química, Universidade Federal de Santa Catarina, 88040-900 Florianópolis - SC, Brazil
}

\begin{abstract}
Neste trabalho foram construídos eletrodos seletivos para o surfactante dodecilsulfato de sódio (SDS) e para brometo, respectivamente, eletrodo indicador e de referência, para medidas potenciométricas. Os eletrodos foram utilizados em solução de SDS e em mistura de SDS e poli(oxietileno) (PEO). Os perfis de potencial da célula $(E)$ versus a concentração de SDS, na ausência e em presença de $0,5 \%$ de $\mathrm{PEO}$, são sensíveis ao processo de associação cooperativa entre SDS e PEO e indicativos de parâmetros como concentração crítica de agregação, cac, e concentração de saturação do polímero, psp. Os parâmetros obtidos por esta metodologia estão em concordância com os obtidos por técnicas clássicas como a de tensão superficial e a de condutividade elétrica.
\end{abstract}

Surfactant-selective electrodes to sodium dodecyl sulfate (SDS) monomer and bromide were constructed, respectively, electrode idicator and reference electrode. The electrodes were tested for solutions of SDS and in mixture of SDS and poly(ethylene oxide) (PEO). The profiles obtained measuring the potential $(E)$ versus SDS concentration in the presence of $0.5 \%$ PEO are sensitive to polymer-surfactant parameters such as the onset of cooperative association of SDS to PEO, the critical aggregation concentration (cac), and the polymer saturation by SDS monomers (psp). The obtained parameters are in agreement with those values found by surface tension and electrical conductivity.

Keywords: surfactant selective electrode, polymer surfactant interaction, poli(ethylene oxide), sodium dodecyl sulfate

\section{Introduction}

Interactions between polymer and ionic surfactants in aqueous solutions have been extensively investigated using different techniques. ${ }^{1-5}$ In general, the results of all available techniques are consistent with a cooperative process which starts at surfactant concentrations lower than the regular critical micellar concentration, $\mathrm{cmc}$. This concentration is usually denoted by critical aggregation concentration, cac. ${ }^{6}$ For ionic surfactants, such as regular ionic micelles, the bound micelles to polymer, so called surfactant-polymer complexes, are strongly influenced by agents such as electrolytes, which affect the micellar electrostatic surface interactions.

The most used techniques for monitoring the polymersurfactant association are surface tension and electrical conductivity first described, by Jones ${ }^{7}$ and Schwuger ${ }^{8}$ for mixtures of PEO and SDS. For non-ionic water-soluble

\footnotetext{
*e-mail:rizzatti@qmc.ufsc.br
}

polymer and anionic surfactants, both plots exhibit two breakpoints: the first, mentioned above, is the cac and the second is generally related to the saturation of the polymer by surfactant monomers, known as the polymer saturation point (psp). Historically, these limiting concentrations are referred to as $T_{1}$ and $T_{2}$, respectively. ${ }^{7}$ In the surfactant concentration region of cac-psp, the development of micelle-like aggregates which complexe with the polymer is assumed, and above the psp, the coexistence of the aggregates and regular aqueous micelles in dynamic equilibrium has been postulated. ${ }^{7-11}$

A versatile and alternative technique, capable of monitoring the surfactant to polymer binding, utilizes surfactant selective electrodes. ${ }^{12-14}$ In principle, the electrode monitors the monomer concentration of the surfactant in a polymer-surfactant mixture, which is an ambiguous determination by other techniques. It can lead also to the determination of important micellar parameters such as the binding isotherm and properties such as the degree of micellar counterion ionization. ${ }^{14}$ The parameters cac and psp, can easily be determined from the plot of cell 
potential versus [Surf.] ${ }^{12}$ (The square brackets here and throughout the text indicate molar concentration).

In recent decades, surfactant electrodes using a permeable selective membrane as the sensor and halogenated ion electrodes as the reference, have been used in several analytic applications and in the study of the surfactant behavior in solution. In this study, we report results on electrodes constructed of liquid membranes for SDS and electrodes for bromide constituted by a mixture of silver bromide and silver sulfide. The results were compared with those obtained with electrodes of the Cole-Parmer model 27502-45, for the surfactant and model 27502-04, for bromide.

\section{Experimental}

\section{Materials}

Poly(ethylene oxide) weight-average 10,000 supplied by Aldrich Chemical Company and poly(vinyl chloride) (PVC) (Sigma), were used as received. The Sodium dodecyl sulfate supplied by Sigma and the dodecyltrimethylammonium bromide (DTAB) and the plasticizer, dibutyl phthalate, supplied by Aldrich Chemical Company, were used as received. The reagents sodium bromide, silver nitrate and sodium sulfite were supplied by Sigma. All solutions were prepared with water, which was distilled and demineralized in a Millipore Milli-Q Water System.

\section{Surfactant-selective membrane electrodes}

Separate solutions of the surfactants, $1.4420 \mathrm{~g}$ SDS and $1.5415 \mathrm{~g}$ DTAB, were mixed and the precipitate was separated by filtration. The final product was purified by recristalization (twice) in acetone and dried under vacuum. The SDS-selective membrane used in the present work was prepared according to the Win-Jones procedure. ${ }^{13,14}$ Typically, to a volume of $10 \mathrm{~mL}$ tetrahydrofurane, $1.0 \mathrm{~g}$ PVC and $0.0012 \mathrm{~g}$ surfactant mixture (SDS/DTAB) were added and the mixture was stirred to give a homogeneous solution. $1.5 \mathrm{~g}$ of plasticizer were then added. The excess solvent was removed under vacuum. The resulting membrane consists of $40 \% \mathrm{~m} / \mathrm{m}$ PVC and $60 \% \mathrm{~m} / \mathrm{m}$ plasticizer. The electrodes were prepared with pieces of polymeric membrane fixed onto a glass tube with a size of $10 \times 1 \mathrm{~cm}$. The inner material consisted of a silver wire covered with silver bromide, immersed to a solution of $0.01 \mathrm{~mol} \mathrm{~L}^{-1} \mathrm{NaBr}$ and SDS.

\section{Selective electrode for bromide}

A mixture of $\mathrm{AgBr} / \mathrm{Ag}_{2} \mathrm{~S}$ was prepared according to Lima and Machado. ${ }^{15}$ Pellets with molar ratios of 1:1, 1:2 and 2:1 $\mathrm{AgBr} / \mathrm{Ag}_{2} \mathrm{~S}$ were prepared by submitting them to a pressure of $3 \times 10^{6} \mathrm{~Pa}$ and glueing them to separate glass tubes with the above described size. The electrodes for bromide without inner solution, were prepared by glueing the pellets with conductive material (graphite/Araldite) to a sheet of copper. The electrode for bromide with inner solution was prepared with silver wire in $0.001 \mathrm{~mol} \mathrm{~L}^{-1}$ $\mathrm{NaBr}$. All electrodes were tested in $10^{-6}-10^{-1} \mathrm{~mol} \mathrm{~L}^{-1}$ solutions of $\mathrm{NaBr}$, in the absence and presence of $0.1 \mathrm{~mol}$ $\mathrm{L}^{-1} \mathrm{KNO}_{3}$. The results (see below) were compared with those obtained using a commercial selective-bromide electrode.

The measurements were performed at $25^{\circ} \mathrm{C}$ and all solutions were made up in sodium bromide $10^{-4} \mathrm{~mol} \mathrm{~L}^{-1}$. Figure 1 shows a scheme of the system designed to measure dodecyl sulfate monomer concentration.

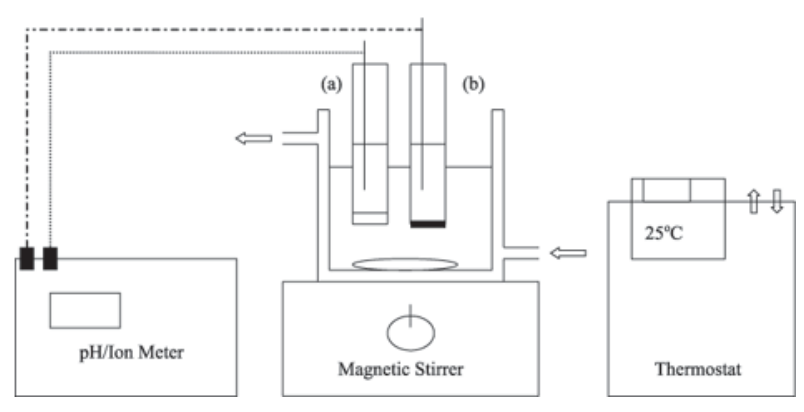

Figure 1. Scheme of the system designed to monitor the SDS monomer titration indicating the (a) selective membrane electrode for the surfactant and the reference, (b) the electrode for bromide with inner solution.

\section{Electrochemical measurements}

Values of cmc, cac and psp were obtained from the discontinuities of the potential $(E)-[\mathrm{SDS}]$ profiles in the presence and absence of $0.5 \%$ PEO. The potential was measured by using a Orion 720A pH/Ion Meter. Normally, the methodology consists of the addition of a SDS solution, using a micropipette, into the cell containing an appropriate volume of distilled water, at $25.0 \pm 0.2^{\circ} \mathrm{C}$. All titrations carried aut in $10^{-4} \mathrm{~mol} \mathrm{~L}^{-1} \mathrm{NaBr}$.

\section{Results and Discussion}

Table 1 lists values for angular coefficient (B), correlation (R), and linear range (LR) for all electrodes for bromide.

Figure 2 shows the calibration curves for the electrodes for bromide with inner solution in the absence and presence of $0.1 \mathrm{~mol} \mathrm{~L}^{-1} \mathrm{KNO}_{3}$.

Among the electrodes tested, the most suitable was that with $0.25 \mathrm{~g}$ of $\mathrm{AgBr} / \mathrm{Ag}_{2} \mathrm{~S}(2: 1)$ and inner solution (see Table 1), in the range of $5 \times 10^{-5}-10^{-1} \mathrm{~mol} \mathrm{~L}^{-1}$ bromide, which 
Table 1. Values of slope (B), correlation (R) and linear range (LR) for the constructed electrodes. The parameter LR represents the interval of bromide concentration in which the plots of potential $(E)$ versus the $\log$ of bromide molar concentration is linear. The commercial electrode is a Cole-Palmer 27502-04

\begin{tabular}{|c|c|c|c|}
\hline $\begin{array}{l}\mathrm{AgBr} / \mathrm{Ag}_{2} \mathrm{~S} \\
\text { Electrodes }\end{array}$ & $-\mathrm{B} / \mathrm{mV}$ & $\mathrm{R}$ & $\mathrm{LR} /\left[\mathrm{Br}^{-}\right]$ \\
\hline $0.25 \mathrm{~g}(1: 1)$ & 77 & 0.9957 & $\left(5 \times 10^{-5}-10^{-2}\right)$ \\
\hline $0.25 \mathrm{~g}(1: 1)^{\mathrm{a}}$ & 78 & 0.9947 & $\left(5 \times 10^{-5}-10^{-2}\right)$ \\
\hline $0.30 \mathrm{~g}(1: 1)$ & 49 & 0.9744 & $\left(10^{-5}-10^{-3}\right)$ \\
\hline $0.30 \mathrm{~g}(1: 1)^{\mathrm{a}}$ & 45 & 0.9946 & $\left(5 \times 10^{-6}-10^{-1}\right)$ \\
\hline $0.25 \mathrm{~g}(1: 2)$ & 80 & 0.9975 & $\left(5 \times 10^{-6}-10^{-1}\right)$ \\
\hline $0.25 \mathrm{~g}(1: 2)^{\mathrm{a}}$ & 58 & 0.9991 & $\left(5 \times 10^{-6}-10^{-1}\right)$ \\
\hline $0.30 \mathrm{~g}(1: 2)$ & 70 & 0.9975 & $\left(5 \times 10^{-6}-10^{-1}\right)$ \\
\hline $0.30 \mathrm{~g}(1: 2)^{\mathrm{a}}$ & 47 & 0.9938 & $\left(10^{-4}-10^{-1}\right)$ \\
\hline $0.30 \mathrm{~g}(2: 1)$ & 78 & 0.9947 & $\left(10^{-5}-10^{-2}\right)$ \\
\hline $0.30 \mathrm{~g}(2: 1)^{\mathrm{a}}$ & 47 & 0.9938 & $\left(5 \times 10^{-5}-10^{-1}\right)$ \\
\hline $0.25 \mathrm{~g}(1: 2)^{\mathrm{b}}$ & 97 & 0.9978 & $\left(5 \times 10^{-5}-10^{-1}\right)$ \\
\hline $0.25 \mathrm{~g}(1: 2)^{\mathrm{a}, \mathrm{b}}$ & 52 & 0.9984 & $\left(5 \times 10^{-5}-10^{-1}\right)$ \\
\hline Commercial & 65 & 0.9993 & $\left(10^{-6}-10^{-1}\right)$ \\
\hline \multicolumn{4}{|l|}{ Electrode } \\
\hline Commercial & 53 & 0.9970 & $\mid\left(5 \times 10^{-5}-10^{-1}\right)$ \\
\hline Electrode $^{\mathrm{a}}$ & & & \\
\hline
\end{tabular}

${ }^{\mathrm{a}}$ The analyses were carried out in the presence of $0.1 \mathrm{~mol} \mathrm{~L}^{-1} \mathrm{KNO}_{3}$; ${ }^{b}$ Inner material electrode consisting of a silver wire covered with silver bromide, immersed to a solution of $0.001 \mathrm{~mol} \mathrm{~L}^{-1} \mathrm{NaBr}$.

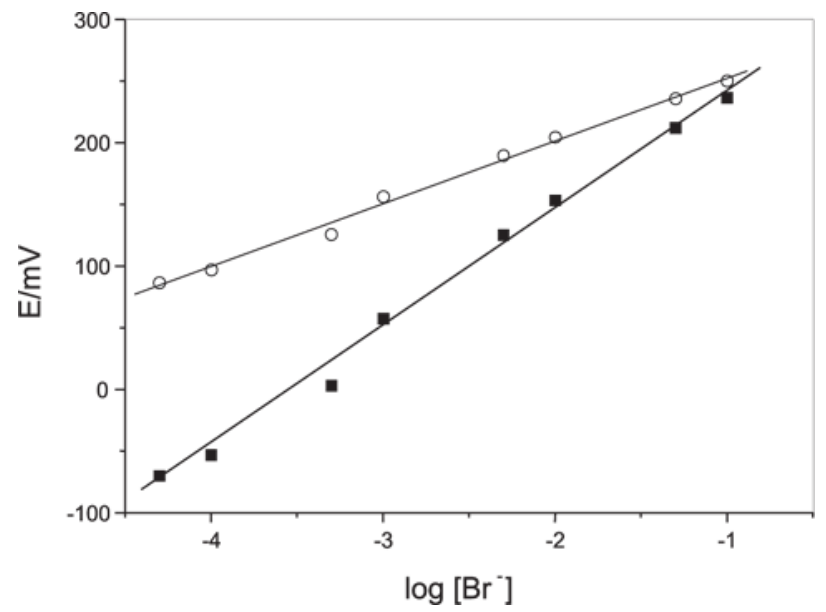

Figure 2. Linear changes of $\log \left[\mathrm{Br}^{-}\right]$for the electrodes with inner solution, in the absence $(\mathbf{\square})$ and presence $(O)$ of $0.1 \mathrm{~mol} \mathrm{~L}^{-1} \mathrm{KNO}_{3}$.

gave a linear correlation of cell potential versus bromide concentration plotted in logarithmic scale. This electrode, in comparison with the commercial bromide electrode, gave better results on the polymer-surfactant studies (see Figure 3).

Figure 3 shows the cell potential as a function of SDS concentration in the absence and presence of PEO, obtained using Cole-Parmer 27502-45 and 27502-04 electrodes. In the absence of PEO, the minimum occurring at ca. $0.007 \mathrm{~mol} \mathrm{~L}^{-1} \mathrm{SDS}$ is closer to the cmc of SDS, literature » $0.008 \mathrm{~mol} \mathrm{~L}^{-1} \cdot{ }^{16}$ With the addition of PEO, $E$ values deviate from those with SDS alone at around to the

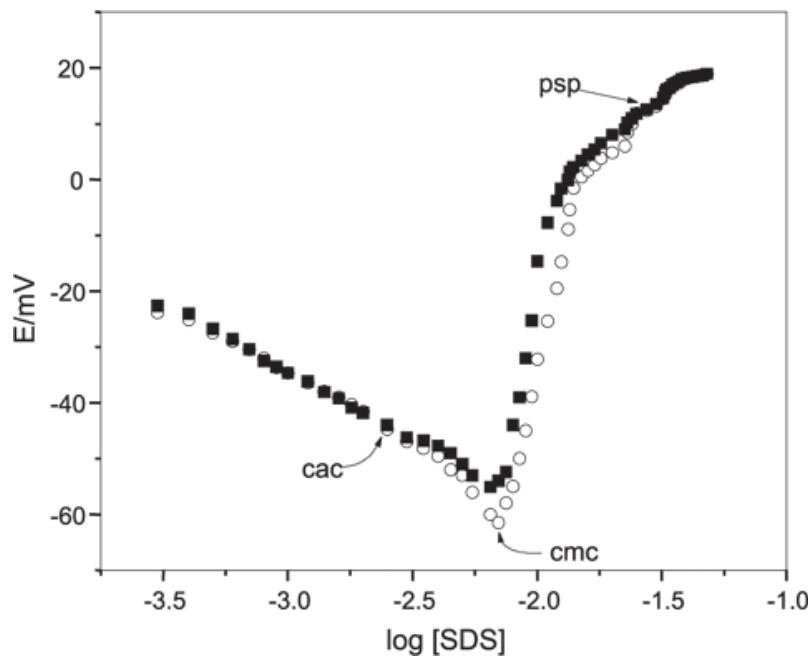

Figure 3. Changes in cell potential as a function of log [SDS] in the absence $(\bigcirc)$ and presence $(\square)$ of $0.5 \%$ PEO by using commercial electrode for SDS and commercial electrode for bromide. The values obtained were cac $=3 \times 10^{-3} \mathrm{~mol} \mathrm{~L}^{-1}$, psp $=28 \times 10^{-3} \mathrm{~mol} \mathrm{~L}^{-1}$ and $\mathrm{cmc}=7.3 \times 10^{-3} \mathrm{~mol} \mathrm{~L}^{-1}$.

expected cac, literature $=0.004 \mathrm{~mol} \mathrm{~L}-1 .{ }^{17}$ This deviation is in the region where the SDS starts to bind cooperatively to the polymer chain, which continues in the presence of PEO and in its absence the profiles eventually merge again (see Figure 3). This SDS concentration is conventionally attributed to polymer saturation, here equal to $0.028 \mathrm{~mol}$ $\mathrm{L}^{-1}$ which closely agrees with literature value, $\mathrm{psp} \mid 0.03$ mol L-1 SDS. ${ }^{17}$ Above this point, the formation of only regular SDS micelles in equilibrium with PEO-SDS complexes is expected. . $^{7,8,11}$

Since above the psp breakpoint the physico-chemical properties of the bulk are driven by the micelle aggregates, the fact that in Figure 4 the $E$ values obtained in the presence and absence of PEO merge to the same values, strongly indicates the formation of only regular SDS micelles when SDS concentration is higher than the psp.

Figure 4 shows the profiles of $E$ versus $\log$ [SDS] obtained from the SDS-selective membrane electrode, according to the present work, and those for the bromide electrode with inner solution. The profiles shown in Figure 4 , were obtained in the presence and absence of $0.5 \%$ PEO. Observing that the deviation and subsequent merging of the data are more clearly indicated than those discussed above Figure 3. This fact emphasizes the quality of the present SDS-selective electrode and the shapes of the two profiles are similar to those previously described. ${ }^{12-14}$

Values of cac, cmc and psp given from Figures 3 and 4 are taken in Table 2.

One point which we should emphasize here, is to the PEO saturation by SDS (psp), which has been the subject of much discussion and controversy. In general, it is well 


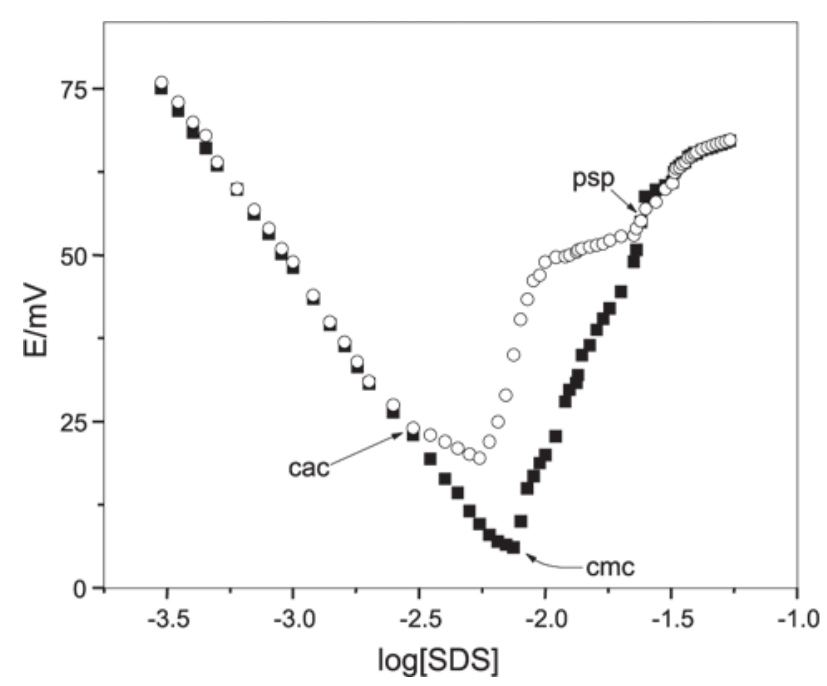

Figure 4. Plots of cell potential as a function of the $\log [\mathrm{SDS}](\bigcirc)$ in the absence and (ם) presence of $0.5 \%$ PEO. The values obtained were cac $=2.9 \times 10^{-3} \mathrm{~mol} \mathrm{~L}^{-1}$, psp $=27 \times 10^{-3} \mathrm{~mol} \mathrm{~L}^{-1}$ and $\mathrm{cmc}=7.5 \mathrm{x}$ $10^{-3} \mathrm{~mol} \mathrm{~L}^{-1}$.

Table 2. Values of the first (cac) and second (psp) breakpoints and cmc, determined by selective-SDS electrodes. In parentheses are the values for the same system obtained by Minatti and Zanette. ${ }^{17}$ Concentrations are given in mol $\mathrm{L}^{-1}$

\begin{tabular}{lccc}
\hline & $10^{3} \mathrm{cac}$ & $10^{3} \mathrm{psp}$ & $10^{3} \mathrm{cmc}$ \\
\hline Figure 3 & $3.0(3.8)^{\mathrm{a}} ;(4.0)^{\mathrm{b}}$ & $28(30)^{\mathrm{a}}$ & $7.3(8.3)^{\mathrm{a}}$ \\
Figure 4 & 2.9 & 27 & 7.5 \\
\hline
\end{tabular}

${ }^{\mathrm{a}}$ Obtained from electrical conductivity; ${ }^{\mathrm{b}}$ Obtained from surface tension.

recognized that the end of SDS binding onto the PEO is indicated by a second breakpoint in the analyzed profile..$^{3,8,10,11,18,19}$ However, questions regarding the interpretation of the second breakpoint have been raised by Minatti and Zanette. ${ }^{17}$ The authors conclude that the second breakpoint in electrical conductivity profiles represent a correct measurement of the polymer saturation only in cases in which the PEO concentration is higher than $0.050 \mathrm{~mol} \mathrm{~L}^{-1}$.

Finally, for surfactant concentrations above the psp, the formation of only regular SDS micelles in equilibrium with PEO-SDS complexes is generally accepted. ${ }^{7,8,11}$ This evidence is supported by the fact that, above the psp, for the properties analyzed such as the electrical conductivity ${ }^{20,21}$ and surface tension, ${ }^{7,22}$ in the presence or absence of PEO, the methods exhibit the same slope for the conductivity-[SDS] plots and the same surface tension values for the surface tension-[SDS] plots, respectively. Based on the above considerations, the same $E$ values obtained in the presence and absence of PEO (Figures 3 and 4), at higher SDS concentrations, strongly indicates also here the formation of only regular SDS micelles. On the analogy of the above techniques, at high SDS concentrations of Figures 3 and 4, the psp can be defined by the onset in which the $\mathrm{E}$ values are identical.

Finally, the differences in the profiles $E$ versus $\log [\mathrm{SDS}]$ in Figures 3 and 4, in the range between cac and psp, must be related to the differences in the interfacial properties between SDS micelles and PEO-SDS complexes. It is well documented that, in the PEO-SDS complexes, the micellar clusters are smaller aggregates and, as a consequence, they are more dissociated than regular SDS micelles. ${ }^{4,11,20,23}$ Therefore, based on this, in comparison to the SDS solution in the absence o PEO, the differences in ionic content explain the higher $E$ values obtained for the solution containing the polymer.

This discussion can be extended to the region of low SDS concentration, below the cac. Two important observations can be stated: (i) the observed $E$ values are identical in the presence and absence of PEO, which indicates that the polymer significantey with the surfactant monomers and (ii) the linearity means that the variation in the cell potential depends linearly on the ionic contents added to the solution. These results are in agreement with the behavior of the electrical conductivity-[SDS] plots, which increase linearly with SDS concentration and the slopes are independent of PEO concentration. ${ }^{4,17,20,21,24}$

\section{Conclusion}

The agreement between the results shown in Table 2 with those previously obtained for a PEO and SDS mixture and for SDS alone using electrical conductivity and surface tension methods ${ }^{17}$ confirms the quality of the SDS-selective electrode constructed in our laboratory. This fact indicates the applicability of this methodology in systems containing more complicated mixtures, for instance, those containing proteins or enzymes and anionic surfactants.

\section{Acknowledgement}

We thank CNPq (Conselho Nacional de Desenvolvimento Científico e Tecnológico) for financial support of this work.

\section{References}

1. Cabane, B.; J. Phys. Chem. 1977, 81, 1639.

2. Gao, Z.; Roderick, E.W.; Kwak, J.C.T.; J. Colloid Interface Sci. 1990, 137, 137.

3. Goddard, E.D.; Ananthapadmanabhan, K.P.; Interactions of Surfactants with Polymers and Proteins, CRC Press: Boca Raton, 1993. 
4. Froehner, S.J.; Belarmino, J.; Zanette, D.; Colloids Surf. A 1998, 137, 131.

5. Winnik, F.M.; Regismond, S.T.A.; Goddard, E.D.; Langmuir 1997, 13, 111.

6. Ruzza, A.A.; Froehner, S.J.; Minatti, E.; Nome, F.; Zanette, D.; J. Phys. Chem. 1994, 98, 12361.

7. Jones, M.N.; J. Colloid Interface Sci. 1967, 23, 36.

8. Schwuger, M.J.; J. Colloid Interface Sci. 1973, 43, 491.

9. Cabane, B.; Duplessix, R.; J. Phys. 1982, 43, 1529.

10. François, J.; Dayantis, J.; Sabbadin, J.; Eur. Polym. J. 1985, 21, 165.

11. Lissi, E.A.; Abuin, E.; J. Colloid Interface Sci. 1985, 105, 1.

12. Bloor, D.M.; Holzwarth, J.F.; Wyn-Jones, E.; Langmuir 1995, 11, 2312.

13. Bloor, D.M.; Holzwarth, J.F.; Wyn-Jones, E.; Langmuir 1995, 11, 2312.

14. Bloor, D.M.; Li, Y.; Wyn-Jones, E.; Langmuir 1995, 11, 3778.

15. Lima, J.L.F.d.C.; Machado, A.A.S.C.; Rev. Port. Quim. 1997, $21,153$.
16. Mukerjee, P.; Mysels, K.J.; Critical Micelle Concentrations of Aqueous Surfactant Systems, National Bureau of Standards: Washington-DC, 1971.

17. Minatti, E.; Zanette, D.; Colloids Surf. A 1996, 113, 237.

18. Dubin, P.L.; Gruber, J.H.; Xia, J.; Zhang, H.; J. Colloid Interface Sci. 1992, 148, 35.

19. Xia, J.; Dubin, P.L.; Kim, Y.; J. Phys. Chem. 1992, 96, 6805.

20. Witte, F.M.; Engberts, J.B.F.N.; J. Org. Chem. 1987, 52, 4767.

21. Zanette, D.F., V.L.A.; J. Colloid Interface Sci. 1999, 213, 379.

22. Santos, S.F.; Zanette, D.; Fischer, H.; Itri, R.; J. Colloid Interface Sci. 2003, 262, 400.

23. Zanette, D.; Soldi, V.; Romani, A.P.; Gehlen, M.H.; Langmuir 2002, 246, 387.

24. Zanette, D.; Ruzza, A.A.; Froehner, S.J.; Minatti, E.; Colloids Surf. A 1996, 108, 91.

Received: August 13, 2003 Published on the web: June 9, 2004 